\title{
Zonasi Tingkat Persebaran Cuaca Ekstrem Kabupaten Sorong Berbasis Geographic Information System (GIS)
}

\author{
Zoning Level of Extreme Weather Distribution in Sorong Regency Based on Geographic \\ Information System \\ Slamet Widodo ${ }^{1 *}$, Murshal Manaf ${ }^{1}$ \\ *Email: slametwdo2810@gmail.com \\ ${ }^{1}$ Program Studi Perencanaan Wilayah dan Kota, Program Pascasarjana, Universitas Bosowa
}

Diterima: 12 Mei 2021 / Disetujui: 02 Agustus 2021

\begin{abstract}
ABSTRAK
Pengaplikasian aplikasi Geographic Information System (GIS) untun mengetahui zonasi tingkat persebaran cuaca ektrem di Kabupaten Sorong telah dilakukan. GIS memetakan secara tepat informasi dan kondisi wilayah sesuai tingkat kerawanan bencana yang terjadi, khususnya bencana cuaca ekstrem di Kabupaten Sorong. Data yang diambil dari Badan Meteorologi, Klimatologi, dan Geofisika Sorong diolah dengan digitasi dan tabulasi melalui aplikasi GIS. Data dianalisis dengan metode deksriptif-kualitatif yaitu dengan menginterpretasi data berdasarkan data kualitatif yang didapatkan dengan fokus pada cuaca ekstrem Kabupaten Sorong meliputi suhu udara, kelembapan, tekana udara, kecepatan angin, penyinaran matahari dan curah hujan. Dari data yang didapatkan, cuaca ekstrem terjadi dibulan Mei dengan tekanan udara 1010,2 mb dan durasi penyinaran matahari terlama selama 6,1 jam. Cuaca ekstrem yang terjadi tidak menyebabkan bencana kekeringan di Kabupaten Sorong. Hasil penelitian ini dapat menjadi bahan informasi dan evaluasi bagi pemerintah dan masyarakat Kabupaten Sorong dalam mengantisipasi terjadinya cuaca ekstrem sehingga mengurangi dampak yang ditimbulkan dari cuaca ekstrem yang akan terjadi Kabupaten Sorong.
\end{abstract}

Kata Kunci: GIS, Cuaca Ekstrem, Hujan,, Kelembaban, Kecepatan Angin, Suhu Udara.

\begin{abstract}
The application of the Geographic Information System (GIS) to determine the zoning level of extreme weather in Sorong Regency has been carried out. GIS application accurately to show informations and conditions of the area according to the level of vulnerability of disasters, especially extreme weather in Sorong Regency. Data from the Meteorology, Climatology and Geophysis Agency of Sorong were processed by digitizing and tabulating through the GIS application. Data were analyzed using descriptive-qualitative method by interpreting data based on qualitative data obtained with a focus on extreme weather in Sorong Regency including air temperature, humidity, air pressure, wind speed, solar radiation and rainfall. From the data has obtained that the extreme weather occurs on May with air pressure at 1010,2 $\mathrm{mb}$ and the longest sunshine duration at 6,1 hours. The extreme weather that occurred did not cause drought in Sorong Regency. The result of this research can be used as information and evaluation for the government and the citizen of Sorong Regency to anticipate the occurance of extreme weather so can to reduce the impact of the extreme weather that will occur in Sorong Regency.
\end{abstract}

Keywords: GIS, Extreme Weather, Rainfall, Humidity, Wind Speed, Air Temperature

(c) () 


\section{A. PENDAHULUAN}

Indonesia merupakan negara kepulauan yang terletak diantara dua benua dan dua samudera. Secara geografis, Indonesia yang terletak di garis kwatulistiwa memiliki dua musim yaitu musim hujan dan musim kemarau. Namun cuaca ekstrem dapat muncul jika terjadi penyimpangan iklim. Salah faktor penyebab terjadinya cuaca ekstrem yaitu angin Monsun Asia. Angin ini melewati Samudera Pasifik sehingga membawa uap air yang cukup intens masuk ke wilayah Indonesia. Selain itu, aliran udara basah dari Samudera Hindia masukm ke wilayah sebelah barat Pulau Sumatera membuat curah hujan di Indonesia meningkat. Adanya pengaruh siklon Blake yang bergerak dari selatan Nusa Tenggara Timur menuju ke Australia. Siklon jenis ini akan memunculkan bibit siklon di wilayah selatan Papua ke Laut Arafuru. Fenomena siklon tersebut berpengaruh terhadap meningkatnya intensitas curah hujan yang ada di wilayah Indonesia.

Kabupaten Sorong yang terletak di Provinsi Papua Barat dapat terkena efek dari siklon Blake. Selain itu, kondisi geografis Kabupaten Sorong yang berada di sebelah utara Samudera Pasifik dan Selat Dampir dan sebelah selatan Laut Seram tentu sangan merasakan dampak dari angin Munson Asia. Hal ini menjadi dasar penulis perlunya mitigasi bencana cuaca ekstrem di Kabupaten Sorong.

Aplikasi Geographic Information System (GIS) digunakan sebagai alat dalam mengolah dan menggambarkan data cuaca ekstrem berdasarkan zona tingkat keparahan di Kabupaten Sorong. GIS merupakan sistem pemetaan dengan integrasi data spasial yang diharapkan mampu memetakan secara tepat informasi dan kondisi wilayah (Setiawan et al, 2011). Selain mudah dalam penggunaannya, GIS juga sangat handal dalam membantu pemerintah dalam mengurangi dampak bencana atau menemukan solusi dalam menanggulangi masalah tertentu yang berkaitan dengan titiktitik rawan bencana di permukaan bumi (Bayuaji et al, 2016), khususnya gambaran cuaca di Kabupaten Sorong. Selain untuk aplikasi pemetaan, GIS juga dapat menggambarkan pemetaan wilayah sesuai dengan tingkat kerawanan bencana yang terjadi, khususnya bencana cuaca ekstrem di Kabupaten Sorong (Gunadi et al, 2015).

Penelitian ini dilakukan untuk memberikan gambaran kepada masyarakat Indonesia, khususnya masyarakat Kabupaten Sorong dalam mengantisipasi terjadinya cuaca ekstrem. Selain itu sebagai mitigasi bencana alam berupa cuaca ekstrem sehingga mengurangi dampak yang ditimbulkan dari cuaca ekstrem di Kabupaten Sorong.

\section{B. METODEPENELITIAN}

Metode yang digunakan dalam penelitian ini adalah metode survei deskriptif. Data yang diolah merupakan data SHP yang bersumber dari Bappeda dan Badan Meterologi, Klimatologi dan Geofisika Kabupaten Sorong. Selain itu, data juga 
diperoleh dari lembaga/instansi berupa materi-materi tentang cuaca, artikel-artikel ilmiah dan jurnal yang dapat menunjang bahan penelitian.

Data SHP dijadikan sebagai data mentah karena format SHP merupakan format data vector yang digunakan untuk menyimpan lokasi, bentuk, dan atribut dari fitur geografis sehingga sangat tepat digunakan untuk aplikasi Geographic Information System (GIS). GIS merupakan sistem yang mengolah data geografis berupa pemasukan, pengelolaan atau manajemen data, manipulasi dan analisis serta keluaran. Pengolahan data dengan menggunakan GIS dilakukan dengan cara digitasi dan tabulasi.

Analisis data menggunakan metode deskriptif-kualitatif, yaitu metode penelitian yang menginterpretasi data berdasarkan data kualitatif yang didapatkan, bukan pada teknik statistik dan matematik. Fokus dalam penelitian ini yaitu cuaca ekstrem meliputi suhu udara, kelembapan, tekanan udaran, kecepatan angin, penyinaran matahari, dan curah hujan.

Wilayah yang dijadikan sebagai sumber penelitian yaitu Kabupaten Sorong yang disesuaikan dengan zonasi cuaca ekstrem yang telah ditentukan sebelumnya, dimana tiap daerah dalam Kabupaten Sorong memiliki titik-titik cuaca ekstrem dengan tingkat zona yang berbeda.

\section{HASIL DAN PEMBAHASAN}

Kabupaten Sorong terletak di Papua Barat dengan luas wilayah 13.075,28 $\mathrm{km}^{2}$ yang terbagi dalam wilayah daratan seluas $8.457 \mathrm{~km}^{2}$ dan wilayah lautan seluas 4.618,28 $\mathrm{km}^{2}$. Berdasarkan Peta Rupa Bumi Bakosurtanal dengan skala 1:250.000, Kabupaten Sorong berada di $130^{\circ} 40^{\prime} 49^{\prime \prime}$ $132^{\circ} 13^{\prime} 48^{\prime \prime}$ BT dan $00^{\circ} 33^{\prime} 42^{\prime \prime}-01^{\circ} 35^{\prime}$ 29" LS. Luas dari masing-masing kecamatan yang berada di Kabupaten Sorong seperti terlihat pada tabel di bawah ini.

Tabel 1. Luas Wilayah Menurut Distrik/ Kecamatan di Kabupaten Sorong

\begin{tabular}{llcc}
\hline No & Kecamatan & Luas & Persentase \\
\hline 1. & Aimas & 222,43 & 1,83 \\
2. & Beraur & 822,26 & 6,76 \\
3. & Klabot & 432,89 & 3,56 \\
4. & Klamono & 488,85 & 4,02 \\
5. & Makbon & 1011,42 & 8,32 \\
6. & Mayamuk & 217,22 & 1,79 \\
7. & Moisegen & 118,62 & 0,98 \\
8. & Salawati & 525,03 & 4,32 \\
9. & Salawati Selatan & 2265,18 & 18,63 \\
10 & Sayosa & 1213,60 & 9,98 \\
11. & Seget & 893,81 & 7,35 \\
12. & Segun & 2021,37 & 16,62 \\
\hline Sumber: & &
\end{tabular}

Dari data luas wilayah diatas, maka dapat digambarkan berdasarkan luas wilayah masing-masing kecamatan menggunakan aplikasi GIS.

Kabupaten Sorong memiliki topografi sangat bervariasi yang terdiri dari pegunungan, lereng, bukit-bukit dan dataran rendah. Selain itu, di bagian timur dikelilingi hutan lebat yang nerupakan hutan lindung dan hutan wisata. Karakteristik wilayah seperti ini memungkinkan terjadinya cuaca ekstrem di beberapa daerah di Kabupaten Sorong. Berikut penjabaran zonasi tingkat kerawanan bencana Kabupaten Sorong menggunakan aplikasi GIS. 


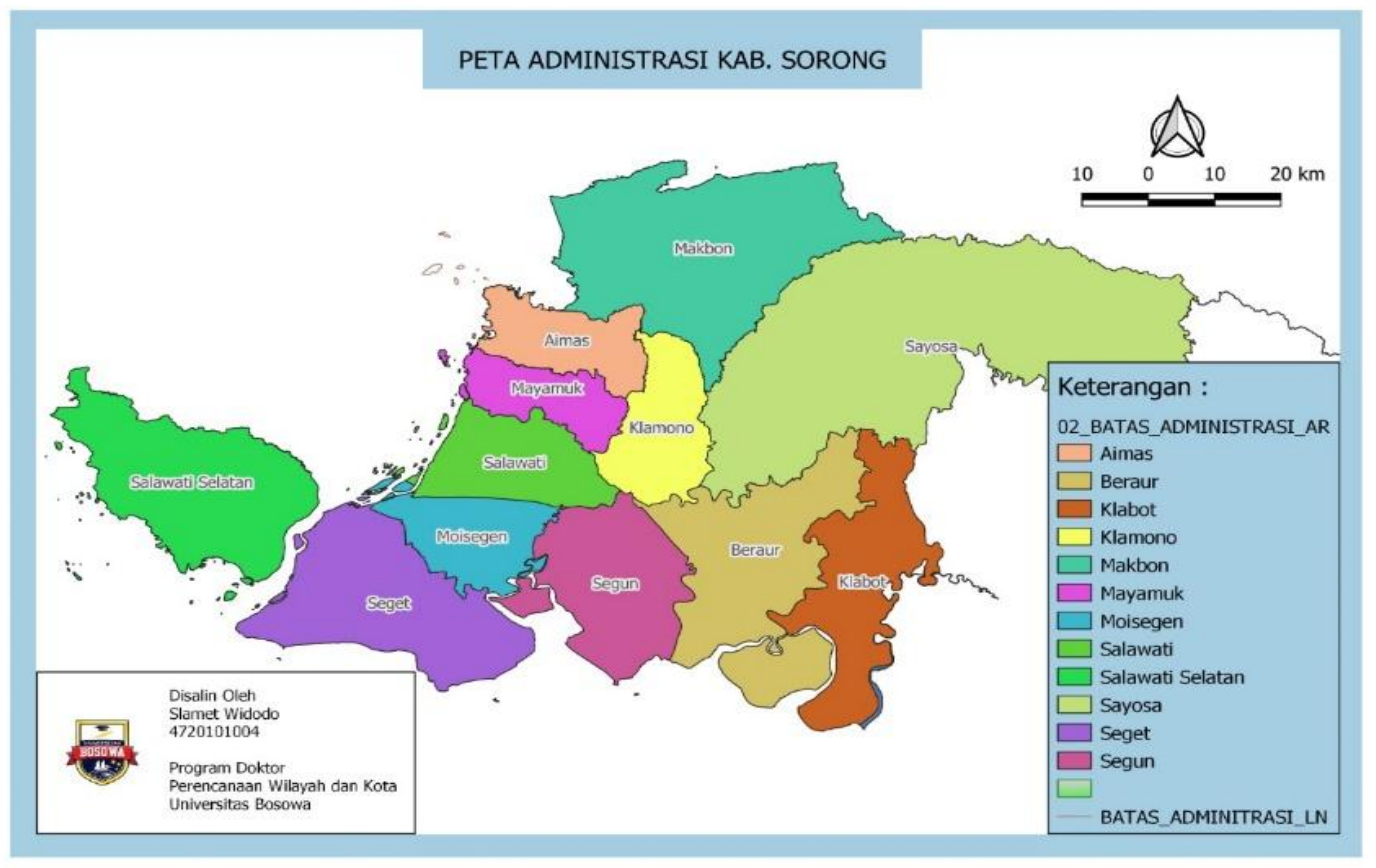

Gambar 1. Peta Administrasi Kabupaten Sorong

Tabel 2. Rata-rata Suhu dan Kelembapan Udara Menurut Bulan di Kabupaten Sorong

\begin{tabular}{lcccccc}
\hline \multirow{2}{*}{ Bulan } & \multicolumn{3}{c}{ Suhu Udara $\left({ }^{\circ} \mathrm{C}\right)$} & \multicolumn{3}{c}{ Kelembaban Udara (\%) } \\
\cline { 2 - 6 } & Maks & Min & Rata-rata & Maks & Min & Rata-rata \\
\hline Januari & 31,8 & 24,8 & 27,4 & 91 & 77 & 85 \\
Februari & 31,7 & 24,8 & 27,5 & 92 & 77 & 84 \\
Maret & 31,7 & 24,7 & 27,5 & 91 & 75 & 85 \\
April & 31,3 & 24,8 & 27,4 & 93 & 83 & 87 \\
Mei & 31,7 & 24,6 & 27,3 & 90 & 82 & 89 \\
Juni & 30,8 & 24,2 & 26,7 & 94 & 83 & 89 \\
Juli & 30,6 & 24,1 & 26,7 & 93 & 83 & 88 \\
Agustus & 30,9 & 24,0 & 26,6 & 93 & 80 & 86 \\
September & 30,7 & 24,1 & 26,7 & 93 & 81 & 92 \\
Oktober & 31,3 & 24,0 & 27,0 & 94 & 77 & 87 \\
November & 31,3 & 24,5 & 27,3 & 94 & 82 & 87 \\
Desember & 31,8 & 25,0 & 27,9 & 94 & 78 & 85 \\
\hline Sumber: Badan Meteorologi, Klimatologi, dan Geofisika Sorong $[6]$. & & &
\end{tabular}

Cuaca ekstrem dipengaruhi oleh beberapa faktor, diantaranya suhu, kelembapan udara, tekanan udara, kecepatan angin dan penyinaran matahari. Data yang terhimpun dalam Badan Meteorologi, Klimatologi, dan Geofisika Kabupaten Sorong tentang faktor-faktor yang mempengaruhi cuaca ektrem disajikan pada Tabel 2 sampai dengan Tabel 4
Dari Tabel 2, diatas menunjukkan suhu udara tertinggi berada di angka $31,8^{\circ} \mathrm{C}$ yang terjadi pada bulan Januari dan Desember 2019. Sedangkan suhu terendah berada pada titik $24,0^{\circ} \mathrm{C}$ di bulan Agustus dan Oktober. Kelembapan udara maksimal berada level 94\% di bulan Juni, Oktober, November, dan Desember) dan level terendah berada pada $75 \%$ di bulan Maret. Namun rerata data suhu 
dan kelembapan udara di Kab. Sorong tidak terjadi perubahan signifikan setiap bulan.

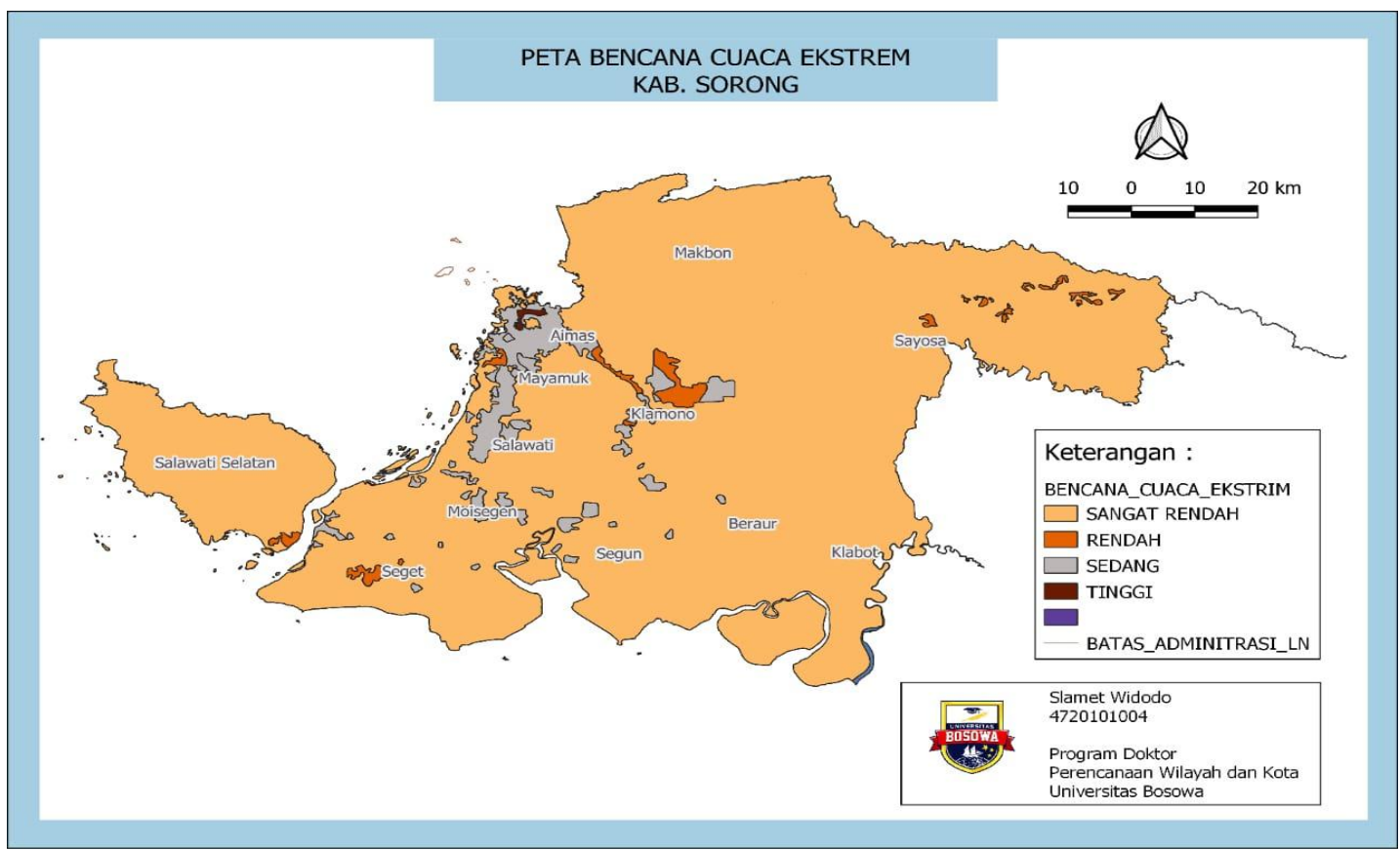

Gambar 2. Peta Bencana Cuaca Ekstrem Kabupaten Sorong

Adapun data tekanan udara, kecepatan angin dan penyinaran matahari setiap bulan di tahun 2019 ditunjukkan pada Tabel 3 dibawah ini.

Tabel 3. Rata-rata Tekanan Udara, Kecepatan Angin dan Penyinaran Matahari Menurut Bulan di Kabupaten Sorong

\begin{tabular}{lccc}
\hline Bulan & $\begin{array}{c}\text { Tekanan } \\
\text { Udara } \\
(\mathrm{mb})\end{array}$ & $\begin{array}{c}\text { Kecepatan } \\
\text { Angin } \\
(\mathrm{knot})\end{array}$ & $\begin{array}{c}\text { Penyinaran } \\
\text { Matahari } \\
\text { (jam) }\end{array}$ \\
\hline Januari & 1000,8 & 4,3 & 5,0 \\
Februari & 1008,8 & 4,2 & 5,8 \\
Maret & 1007,8 & 4,3 & 5,9 \\
April & 1008,6 & 4,7 & 6,0 \\
Mei & 1010,2 & 4,3 & 6,1 \\
Juni & 1009,0 & 4,6 & 5,1 \\
Juli & 1009,8 & 5,2 & 4,4 \\
Agustus & 1010,0 & 6,2 & 5,1 \\
September & 1009,6 & 5,5 & 5,1 \\
Oktober & 1009,8 & 4,6 & 6,0 \\
November & 1009,0 & 3,8 & 4,8 \\
Desember & 1007,8 & 4,4 & 5,3 \\
\hline Sumber: Badan & Meteorologi, Klimatologi, dan & Geofisika \\
Sorong & & &
\end{tabular}

Dari data diatas menunjukkan tekanan udara tertinggi yaitu 1010,2 mb yang terjadi di bulan Agustus. Kecepatan angin yang tertinggi juga terjadi dibulan Agustus dengan kecepatan 6,2 knot. Adapun intensitas penyinaran matahari tertinggi di Kabupaten Sorong pada tahun 2019 terjadi pada bulan Mei waktu penyinaran selama 6,1 jam. Dari keseluruhan data diatas tidak menunjukkan perubahan yang signifikan pada tekanan udara, kecepatan angin dan intensitas penyinaran matahari di Kabupaten Sorong pada tahun 2019.

Dari data analisis aplikasi GIS menunjukkan bahwa cuaca ekstrem hanya terjadi di bagian wilayah Kecamatan Aimas. Cuaca ekstrem dengan tingkat sedang terjadi di kecamatan Seget, Moisegen, Salawati, Mayamuk, Aimas, Kiamono, Segun, dan Beraur. Sedangkan cuaca ekstrem tingkat rendah terjadi di beberapa desa di wilayah Sayosa, Klamono, Mayamuk, Seget, Salawati Selatan, dan Aimas. Sebagian besar wilayah 
Kabupaten Sorong memiliki intensitas cuaca ektrem yang rendah, seperti yang tampak pada Gambar 1.

Adapun efek dari cuaca ekstrem salah satunya yaitu kekeringan. Hal ini dipengaruhi oleh jumlah curah hujan dan lamanya hujan yang terjadi setiap tahun. Dari data Badan Meteorologi, Klimatologi, dan Geofisika Sorong ditunjukkan pada Tabel 4 dibawah.

Tabel 4. Jumlah Curah Hujan dan Hari Hujan Menurut Bulan di Kabupaten Sorong

\begin{tabular}{lcc}
\hline Bulan & $\begin{array}{c}\text { Curah Hujan } \\
\left(\mathrm{mm}^{3}\right)\end{array}$ & Hari Hujan \\
\hline Januari & 169 & 23 \\
Februari & 120 & 17 \\
Maret & 114 & 18 \\
April & 230 & 23 \\
Mei & 310 & 27 \\
Juni & 384 & 25 \\
Juli & 280 & 21 \\
Agustus & 182 & 15 \\
September & 102 & 17 \\
Oktober & 234 & 23 \\
November & 215 & 20 \\
Desember & 179 & 21 \\
Sumber: Badan Meteorologi, Klimatologi, dan Geofisika \\
Sorong
\end{tabular}

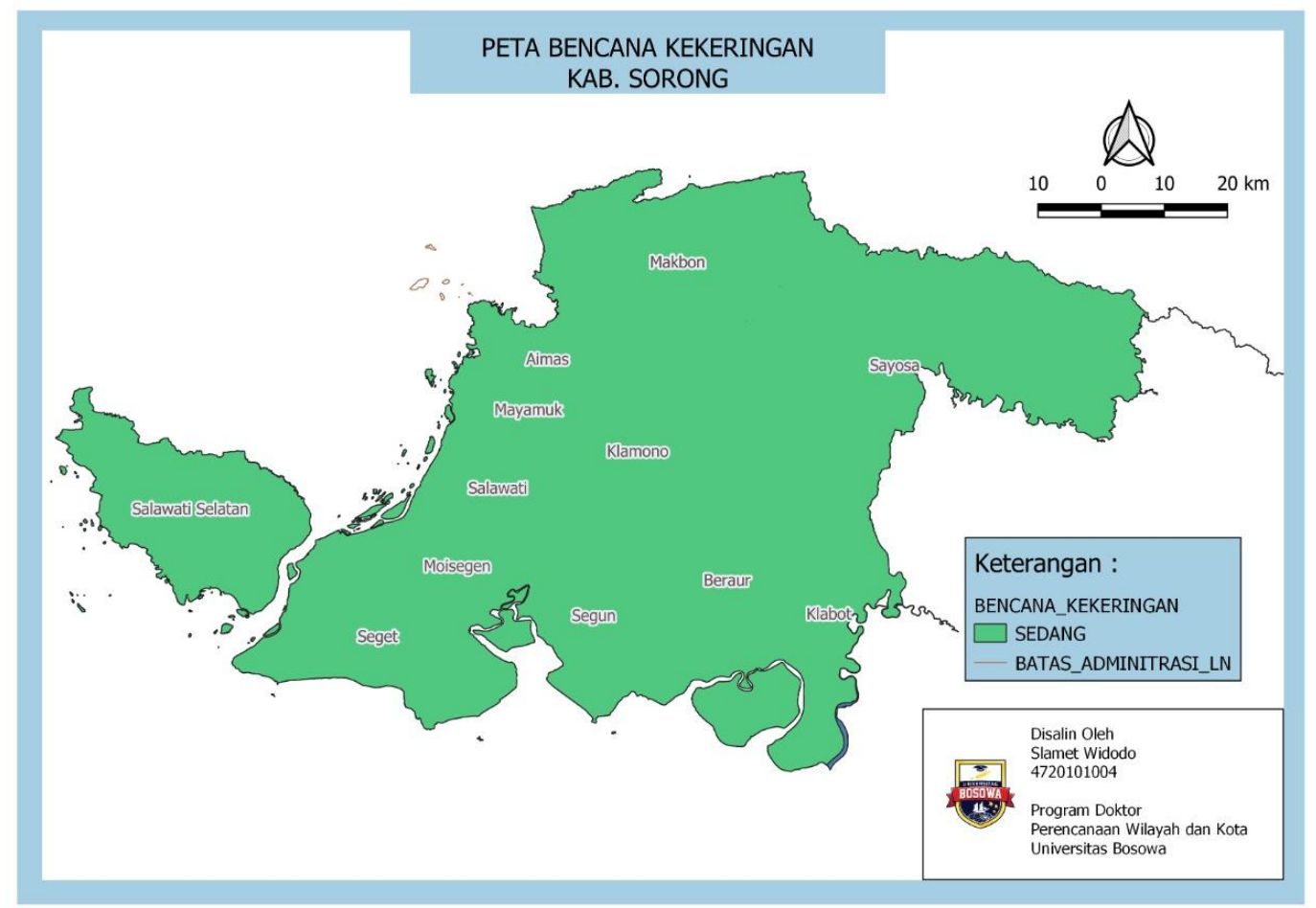

Gambar 3. Peta Bencana Kekeringan Kabupaten Sorong

Curah hujan Kabupaten Sorong terjadi di bulan Juni dengan besaran $384 \mathrm{~mm}^{3}$ yang memiliki 25 hari hujan. Sedangkan curah hujan terendah terjadi pada bulan September dengan intensitas $102 \mathrm{~mm}^{3}$ dengan 17 hari hujan. Adapun hari hujan terlama terjadi di bulan Mei selama 27 hari dengan intensitas curah hujan $310 \mathrm{~mm}^{3}$.

Dari data tersebut menunjukkan tidak terjadi perubahan curah hujan yang signifikan dari bulan ke bulan sehingga curah hujan di Kabupaten Sorong dikategorikan merata di setiap daerah. Hal ini juga ditunjukkan pada 
data analisis aplikasi GIS dimana bencana kekeringan yang terjadi masih dalam kategori sedang diseluruh wilayah Kabupaten Sorong.

Data ini dapat menjadi acuan pemerintah Kabupaten Sorong dalam mengevaluasi dan mencegah kemungkinan terjadinya bencana kekeringan dan cuaca ekstrim lainnya di Kabupaten Sorong.

\section{KESIMPULAN DAN SARAN}

Hasil penelitian dan pembahasan dapat disimpulkan terdapat satu wilayah di Kabupaten Sorong yang mengalami tingkat cuaca ekstrem yang tinggi yaitu Aimas. Dari hasil data Badan Meteorologi, Klimatologi dan Geofisika Kabupaten Sorong, cuaca ekstrem terjadi dibulan Mei dengan tekanan udara 1010,2 mb dan durasi penyinaran matahari terlama yaitu 6,1 jam. Namun cuaca ekstrem yang terjadi tidak menyebabkan bencana kekeringan di Kabupaten Sorong. Penggunaan Geographic Information System (GIS) sangat tepat dalam menggambarkan zonasi tingkat penyebaran cuaca ektrem di Kabupaten Sorong. Hal ini didasarkan pada data yang diperoleh dari Badan Meteorologi, Klimatologi dan Geofisika Kabupaten Sorong sejalan dengan hasil analisis data menggunakan aplikasi GIS.

\section{DAFTAR PUSTAKA}

Badan Meteorologi, Klimatologi, dan Geofisika Kabupaten Sorong. 2019. Shapefile Cuaca Ekstrem Kabupaten Sorong Tahun 2019. Pemerintah Kabupaten Sorong.

Briandana Januar Aji Gunadi, Arief Laila Nugraha, Andri Suprayogi. 2015. Aplikasi Pemetaan Multi Resiko
Bencana di Kabupaten Banyumas menggunakan Open Source Software GIS. Jurnal Geodesi Undip Vol. 4 No. 4.

Dennis F. Niode, Yaulie D. Y. Rindengan, Stanle D. S. Karouw. 2016 .Geographical Information System (GIS) untuk Mitigasi Bencana Alam Banjir di Kota Manado. E-Journal Teknik Elektro dan Komputer Vol. 5 No. 2.

Dhuha Ginanjar Bayuaji, Arief Laila Nugraham Abdi Sukmono. 2016. Analisis Penentuan Zonasi Resiko Bencana Tanah Longsor Berbasis Sistem Informasi Geografis. Jurnal Geodesi Undip Vol. 5 No. 1.

Setiyawidi, Iwan Setiawan, Lili Somantri. 2011. Pemanfaatan Sistem Informasi Geografis untuk Zonasi Tingkat Kerawanan Bencana Letusan Gunung Api Tangkubanparahu. Gea, Vol. 11 No. 2.

Taufik Eka Ramadhan, Andri Suprayogi, Arief Laila Nugraha. 2017. Pemodelan Potensi Bencana Tanah Longsor menggunakan Analisis SIG di Kabupaten Semarang. Jurnal Geodesi Undip Vol. 6 No. 1. 